\title{
First-principles study of fission gas incorporation and migration in
}

\section{zirconium nitride}

\author{
Zhi-Gang Mei,* Linyun Liang, Abdellatif M. Yacout \\ Argonne National Laboratory, 9700 South Cass Avenue, Lemont, IL 60439 - USA
}

\begin{abstract}
To evaluate the effectiveness of $\mathrm{ZrN}$ as a diffusion barrier against fission gases, we investigate the incorporation and migration of fission gas atoms, with a focus on $\mathrm{Xe}$, in $\mathrm{ZrN}$ by firstprinciples calculations. The formations of point defects in $\mathrm{ZrN}$, including vacancies, interstitials, divacancies, Frenkel pairs, and Schottky defects, are first studied. Among all the defects, the Schottky defect with two vacancies as first nearest neighbor is predicted to be the most favorable incorporation sites for the fission gas $\mathrm{Xe}$ in $\mathrm{ZrN}$. The migration of $\mathrm{Xe}$ gas atom in $\mathrm{ZrN}$ is investigated through two diffusion mechanisms, i.e., interstitial and vacancyassisted diffusions. The migration barrier of Xe gas atom through the intrinsic interstitials in $\mathrm{ZrN}$ is considerably lower than that through vacancies. Therefore, at low temperatures fission gas $\mathrm{Xe}$ atoms diffuse mainly through interstitials in single crystal $\mathrm{ZrN}$, whereas at high temperatures $\mathrm{Xe}$ may diffuse in $\mathrm{ZrN}$ assisted by vacancies.
\end{abstract}

Keywords: Zirconium nitride; Defect incorporation and migration; First-principles

* Corresponding author.

E-mail address: zmei@anl.gov (Z. G. Mei) 


\section{INTRODUCTION}

Uranium-molybdenum alloys are under investigation as candidate fuels for future high-performance research reactors using low-enriched uranium. ${ }^{1,2}$ When used as dispersion fuel with aluminum, a significant amount of interaction products form at the interface between the U-Mo fuel particle and the surrounding $\mathrm{Al}$ during in-pile radiation tests, which results in unacceptable swelling in the U-Mo/Al dispersion fuel at high burnups. ${ }^{3}$ Several coating materials, including $\mathrm{Si}^{4}{ }_{\mathrm{ZrN}}{ }^{4} \mathrm{U}$-silicide, ${ }^{5}$ and $\mathrm{U}$-nitride, ${ }^{5}$ were proposed as diffusion barriers to reduce the interaction between the fuel particle and the Al matrix. These coatings help reduce the formation of the interaction layer and therefore decrease the fuel swelling. Because of its superior thermophysical properties, $\mathrm{ZrN}$ is currently selected as a candidate diffusion barrier material for the U-Mo dispersion fuel lead by the European Dispersion Fuel program. Under neutron irradiations, various kinds of defects can form in the diffusion barrier coatings, which may act as incorporation sites for fission gases. The fission gases generated from the UMo fuel can form solution in $\mathrm{ZrN}$ or migrate out of the coating. Meanwhile, $\mathrm{ZrN}$ has also been investigated as a nuclear fuel component in mixed nitride fuels, such as $(\mathrm{U}, \mathrm{Zr}) \mathrm{N}$ and $(\mathrm{Pu}, \mathrm{Zr}) \mathrm{N}$. Research shows that nitride fuels, if in solution with $\mathrm{ZrN}$, exhibit better swelling behavior and thus a reduced interaction between the cladding and the nitride fuel. ${ }^{6}$ Therefore it is important to study the fission gas behavior in the nonfissile components of the mixed nitride fuels, i.e., $\mathrm{ZrN}$.

Recently we studied the thermodynamic and kinetic stability of $\mathrm{ZrN}$ coatings with respect to the Al matrix and U-Mo fuel using first-principles calculations. ${ }^{7}$ However, few studies have been done on the diffusion behaviors of inert gases in $\mathrm{ZrN}$. Tsetseris et al. studied the structure and interaction of point defects in transition-metal nitrides, including $\mathrm{ZrN}$, using first-principles calculations. ${ }^{8-11}$ A limitation of their work is that the crystal structure for defective system was not fully relaxed, which can lead to overestimated formation energy for interstitials and underestimated formation energy for vacancies. Pukati et al. studied the defect 
formation energy in $\mathrm{ZrN}$ and the diffusion of inert gases, including $\mathrm{He}, \mathrm{Kr}$, and $\mathrm{Xe}$, using first-principles calculations. ${ }^{12}$ The incorporation sites and vacancy-assisted migration for fission gases, however, were not systematically studied in their work, both of which are critical for understanding the diffusion mechanism of fission gases in $\mathrm{ZrN}$ coating under irradiation.

To address these limitations, we investigated the incorporation and migration behavior of inert gases, such as $\mathrm{He}, \mathrm{Kr}$, and $\mathrm{Xe}$, in $\mathrm{ZrN}$ using first-principles calculations based on density functional theory. We systematically studied the formation energies of point defects and the incorporation energies of inert gases in these point defects. The diffusion of the gas $\mathrm{Xe}$ in $\mathrm{ZrN}$ was investigated under two mechanisms: interstitial and vacancy-assisted diffusion. Our goal is to obtain a better understanding of fission gas migration behavior in the $\mathrm{ZrN}$ coating and nitride fuels.

The rest of the paper is organized as follows. The computational methods are briefly described in Section II. Detailed results and discussion of the incorporation and migration of inert gases in $\mathrm{ZrN}$ are presented in Section III. In Section IV we briefly summarize our work.

\section{COMPUTATIONAL METHODOLOGY}

The first-principles calculations are performed by the projector augmented wave method as implemented in $\mathrm{VASP}^{13,14}$ within generalized gradient approximation (GGA) parameterized by Perdew et al. ${ }^{15}$ The semi-core $s$ and $p$ states are treated as valence electrons for $\mathrm{Zr}$. In all cases, the total energies are converged to at least $10^{-6} \mathrm{eV} / \mathrm{atom}$. $\mathrm{ZrN}$ adopts the rock salt structure at ambient conditions. The lattice constant of $\mathrm{ZrN}$ after full relaxation is predicted to be $4.596 \AA$, close to the experimental measurement of $4.585 .^{16}$ The relaxed lattice constant is used to generate a $3 \times 3 \times 3$ supercell with $108 \mathrm{Zr}$ and $108 \mathrm{~N}$ atoms, in order to study the defect formation and migration in $\mathrm{ZrN}$. Previous studies showed that the $3 \times 3 \times 3$ supercell is sufficient to satisfy the convergence criterion of the defect formation energy and migration 
energy, less than $0.04 \mathrm{eV} .{ }^{9}$ During the total energy calculations, a plane-wave energy cutoff of $400 \mathrm{eV}$ and a Monkhorst-Pack mesh of $3 \times 3 \times 3 k$-points in the Brillouin zone are employed. The atomic position, cell volume and shape are fully relaxed for all the structures. In order to find the structure with the lowest energy, the symmetry is turned off during the relaxation.

The formation energy $E_{f}$ of a single defect is calculated with the formula,

$$
E_{f}[A]=E_{\text {tot }}[A]-E_{\text {tot }}[\text { bulk }]-\sum_{i} n_{i} u_{i}
$$

where $E_{\mathrm{tot}}[A]$ is the total energy of a supercell containing a defect $A$ and $E_{\mathrm{tot}}[\mathrm{bulk}]$ is the total energy for the perfect crystal using an equivalent supercell. The integer $n_{i}$ indicates the number of atoms of type $i$ that have been added to $\left(n_{i}>0\right)$ or removed from $\left(n_{i}<0\right)$ the supercell to form the defect, and the $\mu_{i}$ is the corresponding chemical potential of the species. For comparison, $\mathrm{HCP} \mathrm{Zr}$ metal and the $\mathrm{N}_{2}$ molecule in vacuum are often used as the reference states for $\mathrm{Zr}$ and $\mathrm{N}$ species to study the defect formation energies. ${ }^{9}$ It should be pointed out that point defects in $\mathrm{ZrN}$ are often charged. However, as adopted in many other DFT studies of defects in nitrides, ${ }^{9,12,19}$ the neglecting of the charge state of defect won't affect the incorporation and migration energies of inert gases in $\mathrm{ZrN}$ predicted in this work.

When isolated defects get close, they may interact with each other and form a defect complex. The binding energy $E_{\text {bonding }}$ of defects $A$ and $B$ in a defect complex $A B$ is obtained by comparing the energy difference between the supercells with single defects $A$ and $B$ and the supercell containing the defect complex $A B$ :

$$
E_{\text {bonding }}=E_{\text {tot }}[A]+E_{\text {tot }}[B]-E_{\text {tot }}[A B]-E_{\text {tot }}[\mathrm{bulk}] \text {. }
$$

In this formulation, a positive binding energy indicates an attraction between defects $A$ and $B$.

The incorporation energy of an inert gas $X$ in the defect $A$ of $\mathrm{ZrN}$ crystal is described as,

$$
E_{\text {inc }}[X]=E_{\text {tot }}[X+A]-E_{\text {tot }}[A]-E_{\text {tot }}[X]
$$


where $E_{\mathrm{tot}}[X+A]$ is the energy of the supercell containing an inert gas $X$ and $\operatorname{defect} A, E_{\mathrm{tot}}[A]$ is the energy of the supercell containing defect $A$, and $E_{\text {tot }}[X]$ corresponds to the energy of an isolated inert gas $X$ in vacuum. The incorporation energy $E_{\text {inc }}$ is defined as the energy needed to incorporate an atom at a pre-existing defect site Therefore, the solution energy of an inert gas atom $X$ in the defect $A$ can be defined as,

$$
E_{\mathrm{sol}}[X]=E_{\mathrm{inc}}[X]+E_{f}[A]
$$

The solution energy describes the energy required to form the defect-inert gas associations.

The migration barriers of inert gas atoms in $\mathrm{ZrN}$ are calculated by the nudged elastic band (NEB) method $^{17}$ to simulate the minimum energy path that passes through the transition state of a diffusion process. To determine the minimum energy path through the NEB method, at least three replicas of the system are created, in each of which the diffusing atom is moved by equidistant steps to intermediate positions between the initial and final states, as obtained by linear interpolation of the path. A large $3 \times 3 \times 3$ supercell is used to ensure that the atoms are separated from their periodic image and provide a more reliable result for the migration barriers of fission gas Xe and defects in the diluted limit.

\section{RESULTS AND DISCUSSION}

We first discuss the formation of vacancies, interstitials, and possible pairs of vacancies and interstitials in $\mathrm{ZrN}$. Next, we investigate the incorporation of the fission gas $\mathrm{Xe}$ at several potential sites in $\mathrm{ZrN}$, and compare its incorporation energy in $\mathrm{ZrN}$ with other fission gases and host materials. We then study the migration behavior of $\mathrm{Xe}$ in $\mathrm{ZrN}$ with different diffusion mechanisms.

\section{A. Single point defects}

We first study the formation of single-point defects, such as vacancy and interstitial, in $\mathrm{ZrN}$. Several configurations are possible for $\mathrm{N}$ and $\mathrm{Zr}$ self-interstitials in $\mathrm{ZrN}$. We consider 
three possible configurations: tetrahedral interstitial, <110> dumbbell (denoted as DB110), and $\langle 111\rangle$ dumbbell (denoted as DB111). The $<100\rangle$ dumbbell configuration is excluded for $\mathrm{N}$ or $\mathrm{Zr}$ interstitial due to high energy cost. Using HCP $\mathrm{Zr}$ metal and the $\mathrm{N}_{2}$ molecule in vacuum as the reference states for $\mathrm{Zr}$ and $\mathrm{N}$ species, the predicted formation energies of vacancies and interstitials in $\mathrm{ZrN}$ are shown in Table I. Among the three configurations of $\mathrm{N}$ interstitials, the tetrahedral interstitial has the lowest formation energy in $\mathrm{ZrN}$, followed by DB110 and DB111 interstitials. The formation energy of the $\mathrm{N}$ vacancy in $\mathrm{ZrN}$ is higher than that of the tetrahedral interstitial but lower than the formation energies of the dumbbell interstitials. The formation energies of $\mathrm{Zr}$ interstitials are found to be considerably higher than that of $\mathrm{N}$, because of its large atomic size. The DB111 interstitial of $\mathrm{Zr}$ is the most stable configuration among the three configurations studied, followed by tetrahedral and DB110 interstitials. Overall, the current prediction of the defect stability in $\mathrm{ZrN}$ is consistent with the study by Tsetseris et al. ${ }^{11}$ However, our predicted formation energies of $\mathrm{N}$ interstitials are lower than those of Tsetseris et al., and the formation energies of $\mathrm{Zr}$ interstitials and N/Zr vacancies are higher. The differences can be ascribed to the different computational schemes to achieve the equlibrium crystal structures, namely, a full relaxation of structure including atomic position, cell volume and shape in our work but only atomic relaxation in Tsetseris et al.'s work.

Table 1. Point defect formation energies in $\mathrm{ZrN}$

\begin{tabular}{lccc}
\hline \hline Defect & $E_{f}(\mathrm{eV})^{\mathrm{a}}$ & $E_{f}(\mathrm{eV})^{\mathrm{b}}$ & $E_{f}(\mathrm{eV})^{\mathrm{c}}$ \\
\hline N vacancy & 3.22 & 1.29 & 3.15 \\
N DB110 interstitial & 3.41 & 5.34 & 3.97 \\
N DB111 interstitial & 3.71 & 5.64 & 4.30 \\
N tetrahedral interstitial & 2.72 & 4.65 & 3.53 \\
Zr vacancy & 2.91 & 1.29 & 2.79 \\
Zr DB110 interstitial & 11.16 & 12.78 & 10.93 \\
Zr DB111 interstitial & 10.41 & 12.03 & 10.11 \\
Zr tetrahedral interstitial & 11.02 & 12.64 & 10.11 \\
\hline \hline
\end{tabular}


${ }^{\mathrm{a}} \mathrm{HCP} \mathrm{Zr}$ metal and $\mathrm{N}_{2}$ gas in vacuum as the reference states for $\mathrm{Zr}$ and $\mathrm{N}$ species.

${ }^{\mathrm{b}}$ The chemical potentials of $\mathrm{Zr}$ and $\mathrm{N}$ species set as $\mu_{\mathrm{Zr}}=-10.14 \mathrm{eV}$ and $\mu_{\mathrm{N}}=-10.23 \mathrm{eV}$, respectively.

${ }^{c}$ Results from Ref. ${ }^{9}$ with $\mathrm{HCP} \mathrm{Zr}$ metal and $\mathrm{N}_{2}$ gas in vacuum as the reference states for $\mathrm{Zr}$ and $\mathrm{N}$ species.

We note that the formation energy of a defect in a compound is not uniquely defined but is a function of the chemical potential of the species. As mentioned earlier, a $\mathrm{N}_{2}$ molecule or an isolated $\mathrm{N}$ atom is often used as the reference state for $\mathrm{N}$ species in the calculation of $\mathrm{N}$ defects in nitride compounds. However, when $\mathrm{ZrN}$ coating is deposited on the U-Mo fuel particles as a diffusion barrier, the chemical potential of $\mathrm{N}$ is far away from that of pure $\mathrm{N}_{2}$ gas. Thus we investigated the effect of $\mathrm{N}$ chemical potential on the defect formation in $\mathrm{ZrN}$. We assume a thermochemical equilibrium in $\mathrm{ZrN}$, and therefore define the range of $\mathrm{Zr}$ and $\mathrm{N}$ chemical potentials as follows: (1) the chemical potentials of $\mathrm{N}$ and $\mathrm{Zr}$ in $\mathrm{ZrN}$ should be lower than those in the most stable form as pure elements; (2) the sum of the chemical potentials of $\mathrm{Zr}$ and $\mathrm{N}$ should be equal to the energy of a bulk $\mathrm{ZrN}$ per molecule; and (3) the formation energies of $\mathrm{N}$ and $\mathrm{Zr}$ vacancies should be positive. With these restraints, the allowed ranges of the $\mathrm{Zr}$ and $\mathrm{N}$ chemical potentials in $\mathrm{ZrN}$ are determined to be $-11.43 \mathrm{eV}<\mu_{\mathrm{Zr}}<-8.85 \mathrm{eV}$ and $11.52 \mathrm{eV}<\mu_{\mathrm{N}}<-8.94 \mathrm{eV}$, respectively. Figure 1 shows the formation energies of the most stable vacancies and interstitials for $\mathrm{Zr}$ and $\mathrm{N}$ in $\mathrm{ZrN}$ as a function of the $\mathrm{N}$ chemical potential. The formation energies of $\mathrm{N}$ vacancy and $\mathrm{Zr}$ interstitial increase with increasing $\mu_{\mathrm{N}}$ while those of the $\mathrm{N}$ interstitial and $\mathrm{Zr}$ vacancy decrease as $\mu_{\mathrm{N}}$ increases. The $\mathrm{Zr}$ interstitial always has the highest formation energy among the four defects. As shown in Fig. 1, the $\mathrm{Zr}$ and $\mathrm{N}$ vacancies have the same formation energy when the $\mathrm{N}$ chemical potential is $-10.14 \mathrm{eV}$. With $\mu_{\mathrm{N}}=-10.14 \mathrm{eV}$ and $\mu_{\mathrm{Zr}}=-10.23 \mathrm{eV}$, we recalculated the formation energies of all point defects in $\mathrm{ZrN}$. As shown in Table 1, with an intermediate $\mathrm{N}$ chemical potential, the vacancy formation energies of $\mathrm{N}$ and $\mathrm{Zr}$ are noticeably lower than those using the pure $\mathrm{N}_{2}$ gas and $\mathrm{Zr}$ metal as the reference states for $\mathrm{N}$ and $\mathrm{Zr}$ species. 


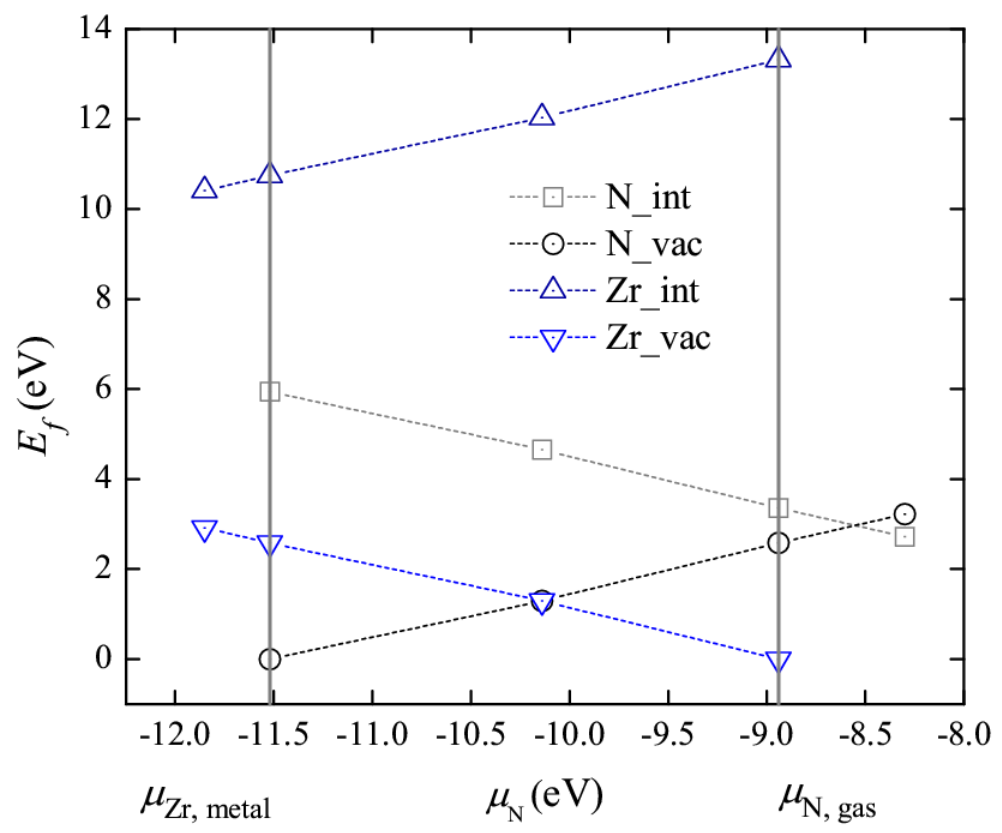

Figure 1. Defect formation energies of the most stable vacancies and interstitials for $\mathrm{Zr}$ and $\mathrm{N}$ in $\mathrm{ZrN}$ as a function of the $\mathrm{N}$ chemical potential. The two vertical lines show the determined range for $\mathrm{N}$ chemical potential. Dotted lines are guides to eyes.

\section{B. Divacancy defect clusters}

As defects get close to each other, some may recombine, such as vacancies and interstitials of the same type of elements, while some may bind with each other and form defect clusters, such as vacancy and interstitial clusters. Vacancy clusters are potential incorporation sites for large fission gases in nuclear fuels. For example, the most stable incorporation site of the fission gas Xe in uranium dioxide is the Schottky defect with three vacancies. ${ }^{18}$ Therefore, we study the formation of $\mathrm{N}$ and $\mathrm{Zr}$ vacancy clusters and the Schottky defect in $\mathrm{ZrN}$ with respect to the vacancy distance. As shown in Table 2, the formation energies of $\mathrm{N}$ and $\mathrm{Zr}$ divacancies decrease as the vacancy distance increases from the first nearest neighbor (1NN) to the second nearest neighbor $(2 \mathrm{NN})$, indicating that the first nearest neighbor divacancies are not stable. In contrast, the formation energies of the Schottky defect 
are less sensitive to the vacancy distance. It should be pointed out that the relaxation scheme for crystal structure can affect the formation energy of vacancy clusters. With a fixed cell volume, the formation energies of divacancies are slightly underestimated. As with single vacancy, the formation energies of divacancies and the Schottky defect decrease if intermediate potentials are used for the $\mathrm{N}$ and $\mathrm{Zr}$ species.

Table 2. Formation energies of divacancies and Schottky defects in $\mathrm{ZrN}$

\begin{tabular}{lllll}
\hline \hline Divacancy Type & $E_{f}(1 \mathrm{NN})$ & $E_{f}(2 \mathrm{NN})$ & $E_{f}(4 \mathrm{NN})$ & $E_{f}(7 \mathrm{NN})$ \\
\hline $\mathrm{N} \mathrm{divacancy}^{\mathrm{a}}$ & 6.51 & 6.42 & 6.43 & \\
$\mathrm{~N} \mathrm{divacancy}^{\mathrm{b}}$ & 2.66 & 2.56 & 2.58 & \\
Zr divacancy $^{\mathrm{a}}$ & 6.17 & 5.91 & 5.79 & \\
Zr divacancy $^{\mathrm{b}}$ & 2.93 & 2.67 & 2.56 & \\
Schottky defect & 2.56 & 2.57 & 2.53 & 2.52 \\
\hline \hline
\end{tabular}

${ }^{\mathrm{a}} \mathrm{HCP} \mathrm{Zr}$ metal and $\mathrm{N}_{2}$ gas in vacuum as the reference states for zirconium and nitrogen species.

${ }^{\mathrm{b}}$ The chemical potentials of $\mathrm{Zr}$ and $\mathrm{N}$ species set as $\mu_{\mathrm{Zr}}=-10.14 \mathrm{eV}$ and $\mu_{\mathrm{N}}=-10.23 \mathrm{eV}$, respectively.

To study the stability of a divacancy with respect to its single vacancy, we calculated the bonding energy between the two single vacancies using Eq. (2). Figure 2 shows the calculated bonding energy in the divacancies and Schottky defect as a function of the vacancy distance. For both the $\mathrm{N}$ and $\mathrm{Zr}$ divacancies, the first nearest-neighbor configuration is unstable, showing a repulsion between the two vacancies, especially for the Zr divacancy. As the vacancy distance increases, the $\mathrm{N}$ and $\mathrm{Zr}$ divacancies start to show a weak attraction at the second and fourth nearest-neighbor distance, respectively. For the Schottky defect, the bonding between the $\mathrm{N}$ and $\mathrm{Zr}$ vacancies is slightly attractive, and the bonding energy between the two vacancies is not very sensitive to the vacancy distance. Therefore, we conclude that the second nearest-neighbor $\mathrm{N}$ divacancy and Schottky defect may form stable divacancy clusters in $\mathrm{ZrN}$, which can act as incorporation sites for large fission gases, such as $\mathrm{Xe}$ and $\mathrm{Kr}$. 


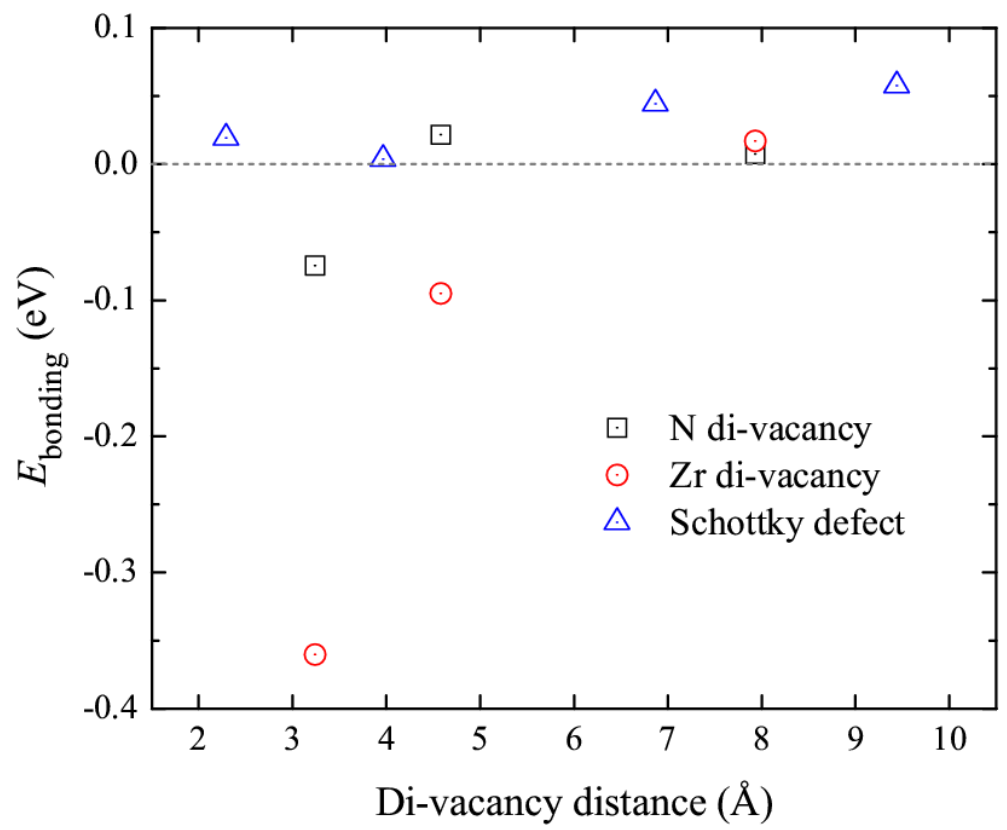

Figure 2. Bonding energy between vacancies as a function of the vacancy distance.

\section{Frenkel pair defects}

Frenkel pair defects are the primary defect type when materials are subject to ion or neutron irradiations. If the interstitial atom gets enough thermal energy, it can diffuse far enough from the correspondent vacancy to form a stable Frenkel pair defect. Because of the formation of vacancies, Frenkel pair defects of $\mathrm{N}$ and $\mathrm{Zr}$ can also serve as potential incorporation sites for fission gas in irradiated $\mathrm{ZrN}$. We studied the formation of $\mathrm{N}$ and $\mathrm{Zr}$ Frenkel pair defects in $\mathrm{ZrN}$ with different configurations for the interstitial defects. Table 3 shows the calculated formation energies of $\mathrm{N}$ and $\mathrm{Zr}$ Frenkel pair defects as a function of the distance between the vacancy and interstitial defects. Overall, the formation energy of a stable $\mathrm{N}$ Frenkel pair is much lower than that of a stable Zr Frenkel pair, less than half the value of Zr. Therefore, the concentration of the N Frenkel pair defect will be much higher than that of the $\mathrm{Zr}$ Frenkel pair in thermal or radiation conditions. For the $\mathrm{N}$ Frenkel pair with $\mathrm{N}$ tetrahedral interstitial as the first nearest neighbor to the $\mathrm{N}$ vacancy, as shown in Fig. 3(a), this configuration is not stable. After atomic relaxation, the $\mathrm{N}$ interstitial atom returns to the 
original vacancy site and then annihilates. As the distance between the defects increases, the $\mathrm{N}$ vacancy and tetrahedral interstitial can form stable Frenkel pairs with a formation energy around $6.0 \mathrm{eV}$. The formation energy of the Frenkel pair slightly decreases as the defect distance increases from second nearest neighbor to fourth nearest neighbor. In comparison, the N Frenkel pair with the N DB110 interstitial as the first nearest neighbor to the $\mathrm{N}$ vacancy, as shown in Fig. 3(b), can form a stable Frenkel pair. However, its formation energy is about $0.8 \mathrm{eV}$ higher than that of the $\mathrm{N}$ vacancy and tetrahedral interstitial Frenkel pair because of the higher formation energy of the nitrogen DB110 interstitial compared with the tetrahedral interstitial. Another configuration of the nitrogen Frenkel pair is to rotate the nitrogen DB110 interstitial by $90^{\circ}$ in the (001) plane, as shown in Fig. 3(c). However, these $\mathrm{N}$ interstitial atoms return to their normal lattice sites after relaxation. Similar to N, the Zr Frenkel pair with tetrahedral interstitial as the first nearest neighbor to the $\mathrm{Zr}$ vacancy, as shown in Fig. 4(a), is not stable. As the distance between the vacancy and interstitial increases, the $\mathrm{Zr}$ vacancy and tetrahedral interstitial can form stable Frenkel pairs with a formation energy of $13.79 \mathrm{eV}$. The $\mathrm{Zr}<111>$ dumbbell interstitial and vacancy can also form Zr Frenkel pairs. As shown in Fig. 4(b), when the $\mathrm{Zr}<111>$ dumbbell interstitial and the vacancy are in the same direction, the $\mathrm{Zr}$ interstitial atoms will move to the regular $\mathrm{Zr}$ lattice sites after relaxation. As the defect distance increases, this $\mathrm{Zr}$ Frenkel pair can be stabilized with a formation energy slightly lower than that of the previous configuration because of the lower formation energy of the $\mathrm{Zr}$ $<111>$ dumbbell interstitial compared with the $\mathrm{Zr}$ interstitial. However, the first nearest neighbor $\mathrm{Zr}<111>$ dumbbell interstitial and vacancy can form a stable Frenkel pair if the $\mathrm{Zr}$ $<111>$ dumbbell interstitial atoms are rotated by $70.5^{\circ}$ in the (-101) plane, as shown in Fig. 4(c). 
Table 3. Frenkel pair formation energies in $\mathrm{ZrN}$

\begin{tabular}{lcccc}
\hline \hline Divacancy Type & $E_{f}(1 \mathrm{NN})$ & $E_{f}(2 \mathrm{NN})$ & $E_{f}(4 \mathrm{NN})$ & $E_{f}(7 \mathrm{NN})$ \\
\hline $\mathrm{N}_{\text {vac }}+\mathrm{N}_{\text {int_tetra }}$ & - & 6.04 & 5.95 & 5.95 \\
$\mathrm{~N}_{\text {vac }}+\mathrm{N}_{\text {int_DB110 }}{ }^{\mathrm{a}}$ & 6.79 & & & \\
$\mathrm{Zr}_{\text {vac }}+\mathrm{Zr}_{\text {int_tetra }}$ & - & 13.79 & 13.37 & 13.37 \\
$\mathrm{Zr}_{\text {vac }}+\mathrm{Zr}_{\text {int_DB111 }}$ & - & 13.76 & 13.27 & 13.29 \\
$\mathrm{Zr}_{\text {vac }}+\mathrm{Zr}_{\text {int_DB111 }}{ }^{\mathrm{c}}$ & 13.35 & & & \\
\hline \hline
\end{tabular}

${ }^{\text {a Nitrogen }}<110>$ dumbbell interstitial as shown in Fig. 3(b).

${ }^{\mathrm{b}}$ Zirconium $<111>$ dumbbell interstitial as shown in Fig. 4(b).

${ }^{\mathrm{c}}$ Zirconium $<111>$ dumbbell interstitial as shown in Fig. 4(c).
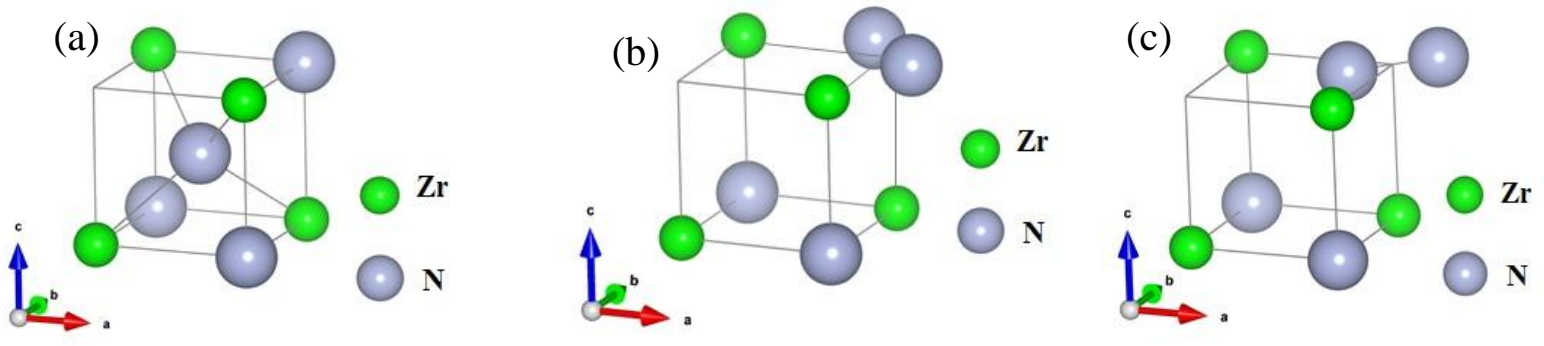

Figure 3. Atomic configurations of $\mathrm{N}$ Frenkel pairs in $\mathrm{ZrN}$ : (a) unstable $1 \mathrm{NN} N$ vacancy and tetrahedral interstitial; (b) stable 1NN nitrogen vacancy and <110> dumbbell interstitial; and (c) unstable 1NN nitrogen vacancy and <110> dumbbell interstitial.

(a)

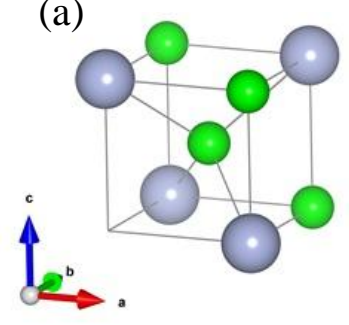

(b)

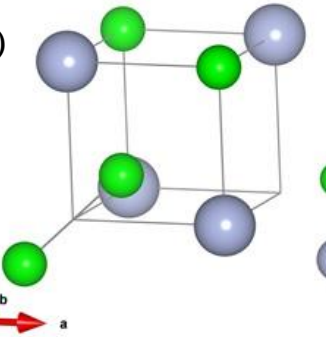

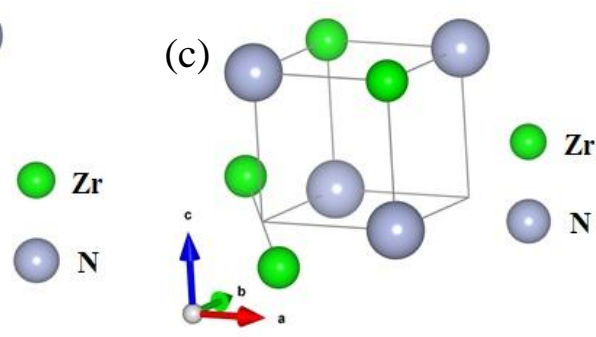

Figure 4. Atomic configurations of $\mathrm{Zr}$ Frenkel pairs in $\mathrm{ZrN}$ : (a) unstable $1 \mathrm{NN} \mathrm{Zr}$ vacancy and tetrahedral interstitial; (b) unstable $1 \mathrm{NN}$ zirconium vacancy and <111> dumbbell interstitial; and (c) stable $1 \mathrm{NN}$ zirconium vacancy and $<111\rangle$ dumbbell interstitial. 
By comparing the formation energy differences between the Frenkel pair and the isolated vacancy and interstitial defects, we can obtain the bonding energy between the vacancy and interstitial in the Frenkel pairs. As shown in Fig. 5, the vacancy and interstitial defects in $\mathrm{N}$ Frenkel pairs have a weak repulsion. The repulsive energy decreases as the distance between vacancy and interstitial increases. As for the $\mathrm{Zr}$ Frenkel pairs, the bonding between the $\mathrm{Zr}$ vacancy and $<111>$ dumbbell interstitial is repulsive initially but changes to attractive when the defect distance is larger than $7.25 \AA$. The $\mathrm{Zr}$ vacancy and tetrahedral interstitial in $\mathrm{ZrN}$ always show attraction because of the high formation energy of the $\mathrm{Zr}$ tetrahedral interstitial.

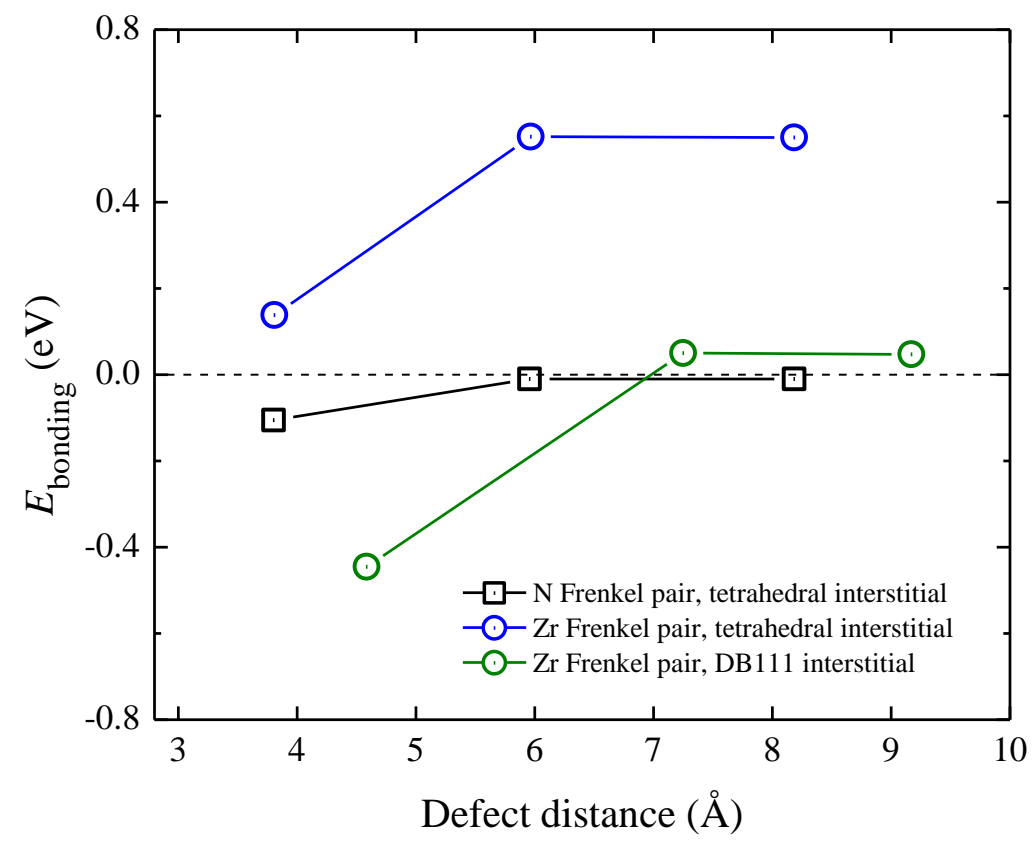

Figure 5. Bonding energy between the vacancy and interstitial in Frenkel pair defects of $\mathrm{ZrN}$ as a function of defect distance. 


\section{Inert gas incorporation}

When fission gases form in nuclear fuels as a result of fission reactions, they can diffuse into $\mathrm{ZrN}$ and become part of the $\mathrm{ZrN}$ lattice. The potential incorporation positions of fission gases in $\mathrm{ZrN}$ include the tetrahedral site, $\mathrm{N} / \mathrm{Zr}$ single-vacancy site, substitution site on the N/Zr lattice site, N/Zr divacancy site, Schottky defect, and N/Zr vacancy site in the N/Zr Frenkel pair defect. We studied 14 incorporation sites in $\mathrm{ZrN}$. Table 4 lists the calculated incorporation energies of the fission gas $\mathrm{Xe}$ in these 14 configurations in $\mathrm{ZrN}$. Note that the incorporation energy shown in Table 4 corresponds to the energy required to incorporate a Xe gas atom in the defective $\mathrm{ZrN}$ crystal.

For a perfect crystal, the simplest incorporation site is the tetrahedral interstitial site $I_{\mathrm{Xe}}$. Because of the large atom size of Xe compared with the relatively small size of the tetrahedral site, this incorporation is highly unstable due to the high-energy cost, $19.24 \mathrm{eV}$. The high formation energyis consistent with the large distortion of the host lattice due to introduction of an interstitial Xe atom. With a single vacancy, the Xe atom in the tetrahedral position can form a stable defect association with the vacancy, namely, $I_{\mathrm{Xe}} V_{\mathrm{Zr}}$ or $I_{\mathrm{Xe}} V_{\mathrm{N}}$. In these configurations, the Xe atom can be trapped in the vacancy positions. The introduced open space of the vacancy notably reduces the incorporation energy of $\mathrm{Xe}$ in $\mathrm{ZrN}$ by $7.48 \mathrm{eV}$ and $9.6 \mathrm{eV}$ for the $\mathrm{N}$ and $\mathrm{Zr}$ vacancies, respectively. The energy reduction is more noticeable in the case of $\mathrm{Zr}$ vacancy than the $\mathrm{N}$ vacancy, which is consistent with the lower lattice distortion in the former case. This can also be explained by the stronger bonding energy between $I_{\mathrm{Xe}}$ and $V_{\mathrm{Zr}}$ of $9.6 \mathrm{eV}$ as compared with that between $I_{\mathrm{Xe}}$ and $V_{\mathrm{N}}$. Bes et al. ${ }^{19}$ studied the incorporation of $\mathrm{Xe}$ in TiN and predicted that the incorporation energy of $\mathrm{Xe}$ in the $\mathrm{N}$ vacancy is lower than the one in the $\mathrm{N}$ vacancy, a prediction that is not consistent with our results. This inconsistence is due to a smaller supercell and fixed volume used during their structural relaxation. As indicated by the relaxation of the interstitial Xe atom to the vacancy site of $\mathrm{N} / \mathrm{Zr}$, Xe substitutions of $\mathrm{N} / \mathrm{Zr}$ atom in $\mathrm{ZrN}\left(S_{X e}^{N}\right.$ and $\left.S_{X e}^{Z r}\right)$ should also be more stable than the 
incorporation in the tetrahedral site. The calculated incorporation energies of Xe substitution at $\mathrm{N}$ and $\mathrm{Zr}$ site are found to be almost the same as those with $\mathrm{Xe}$ in tetrahedral position associated with $\mathrm{N}$ or $\mathrm{Zr}$ vacancy. The incorporation energy of $\mathrm{Xe}$ in the substitution of the $\mathrm{Zr}$ atom is about $2.12 \mathrm{eV}$ lower than that of the $\mathrm{N}$ atom, consistent with the large atomic size of Zr compared with $\mathrm{N}$.

We also studied the Xe interstitial in association with the $\mathrm{N}$ divacancy $\left(I_{\mathrm{Xe}} V_{\mathrm{NN}}\right.$ with $\mathrm{N}$ vacancies as first nearest neighbor), $\mathrm{Zr}$ divacancy $\left(I_{\mathrm{Xe}} V_{\mathrm{ZrZr}}\right.$ with $\mathrm{Zr}$ vacancies as first nearest neighbor), and mixed divacancy ( $I_{\mathrm{Xe}} V_{\mathrm{ZrN}-1 \mathrm{NN}}$ with $\mathrm{Zr}$ and $\mathrm{N}$ vacancies as first nearest neighbor, and $I_{\mathrm{Xe}} V_{\mathrm{ZrN}-2 \mathrm{NN}}$ with $\mathrm{Zr}$ and $\mathrm{N}$ vacancies as second nearest neighbor). The relaxed atomic positions of the Xe gas atom in the N/Zr divacancy and mixed divacancies are illustrated in Fig. 6. The incorporation energy of the Xe interstitial associated with the $\mathrm{N}$ or $\mathrm{Zr}$ divacancy is further reduced compared with their corresponding single-vacancy configurations because of the increased open space, especially for $I_{\mathrm{Xe}} V_{\mathrm{ZrZr}}$. In the case of the $\mathrm{N}$ divacancy, the $\mathrm{Xe}$ interstitial atom relaxes to one of the nitrogen vacancy sites, and the resulting lattice distortion is close to Xe associated with the singe nitrogen vacancy. For comparison, the Xe interstitial atom relaxes to a position slightly off one of the original $\mathrm{Zr}$ vacancy sites by $1.6 \AA$ between the two $\mathrm{Zr}$ vacancies. When the $\mathrm{Xe}$ interstitial is near the mixed $\mathrm{Zr}$ and $\mathrm{N}$ vacancies, it can relax to either a position between these two vacancies slightly close to the $\mathrm{Zr}$ vacancy site in the case of $I_{\mathrm{Xe}} V_{\mathrm{ZrN}-1 \mathrm{NN}}$ or the $\mathrm{Zr}$ vacancy in the case of $I_{\mathrm{Xe}} V_{\mathrm{ZrN}-2 \mathrm{NN}}$. The incorporation energies are $5.91 \mathrm{eV}$ and $9.59 \mathrm{eV}$ for $I_{\mathrm{Xe}} V_{\mathrm{ZrN}-1 \mathrm{NN}}$ and $I_{\mathrm{Xe}} V_{\mathrm{ZrN}-2 \mathrm{NN}}$, respectively. The lowest incorporation energy of $\mathrm{Xe}$ at the first nearest-neighbor $\mathrm{Zr}$ and $\mathrm{N}$ vacancies among all the incorporation sites studied is consistent with its lowest lattice distortion.

We also considered the exchange between a Xe atom in the tetrahedral position and one atom of the lattice. This configuration corresponds that a Xe atom knocks an atom $(\mathrm{N}$ or $\mathrm{Zr}$ ) out of its lattice position such that the lattice atom goes to the tetrahedral interstitial position, a situation that can happen during the irradiation process. In order to simulate this 
phenomenon, the previously simulated incorporation of a Xe atom in the substitution site is associated with a self-interstitial in the tetrahedral position $\left(S_{X e}^{N} I_{N}\right.$ and $S_{X e}^{Z r} I_{Z r}$ for $\mathrm{N}$ and $\mathrm{Zr}$ atoms, respectively). The exchange of interstitial atoms between $\mathrm{Xe}$ and $\mathrm{N}$ at the tetrahedral position can partially decrease the large stress induced by lattice distortion and releases an energy of $1.92 \mathrm{eV}$. Because of the large size of $\mathrm{Zr}$ atom, there is almost no energy gain by exchanging between $\mathrm{Xe}$ and $\mathrm{Zr}$ atoms at the tetrahedral interstitial site, which leads to one of the highest incorporation energies among all the configurations studied.

To quantify the lattice distortion due to the introduction of the $\mathrm{Xe}$ atom in $\mathrm{ZrN}$, we define the lattice strain as $\varepsilon=\frac{a_{\text {distort }}-a_{0}}{a_{0}}$, where $a_{\text {distort }}$ is the lattice constant of the $\mathrm{ZrN}$ crystal with Xe incorporation and $a_{0}$ tis he lattice constant of the pure $\mathrm{ZrN}$ crystal. Figure 7 shows the calculated incorporation energy of $\mathrm{Xe}$ in several different incorporation sites in $\mathrm{ZrN}$ as a function of the lattice strain. The $\mathrm{Xe}$ incorporation energy in $\mathrm{ZrN}$ is roughly linearly proportional to the lattice strain caused by the Xe inclusion. The first nearest-neighbor Schottky defect $\left(I_{\mathrm{Xe}} V_{\mathrm{ZnN}-1 \mathrm{NN}}\right)$ shows the lowest incorporation energy due to the lowest lattice strain after Xe inclusion, while the tetrahedral interstitial $\mathrm{Xe}\left(I_{\mathrm{Xe}}\right)$ and $\mathrm{Xe}$ substitution of $\mathrm{Zr}$ atom associated with tetrahedral interstitial $\mathrm{Zr}\left(S_{X e}^{Z r} I_{Z r}\right)$ have the highest incorporation energies because of the largest lattice strain. In comparison with the study of Xe incorporation in TiN by Bes et al. ${ }^{19}$, our incorporation energies are noticeably lower than their predictions. This discrepancy could be due to several factors. In particular, because of its smaller lattice constant of TiN, the Xe incorporation energy in TiN is slightly higher than that in $\mathrm{ZrN}$. Other reasons are related to the simulation methods used in their studies: (1) a smaller 64-atom supercell was used in their calculations, which can lead to overestimated incorporation energies, and (2) the volume and shape of the supercells were fixed in their simulations, which can lead to overestimated formation energy of interstitials and underestimated formation energy of vacancies. 


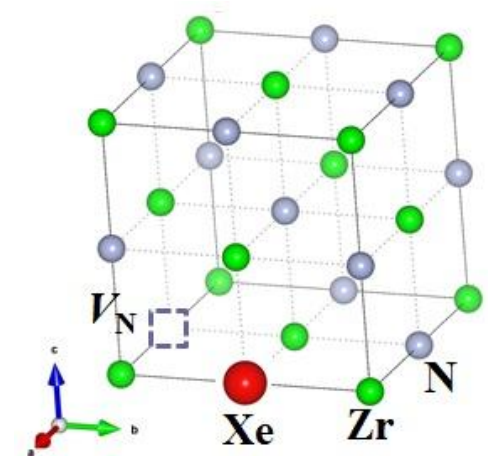

(a)

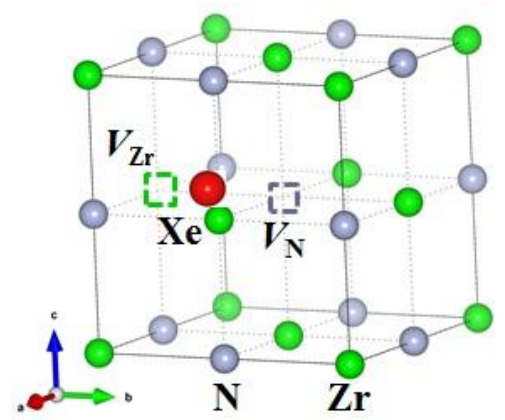

(c)

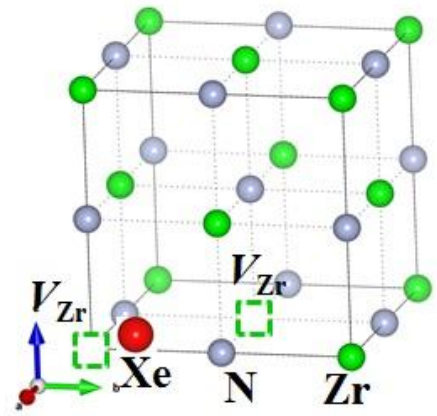

(b)

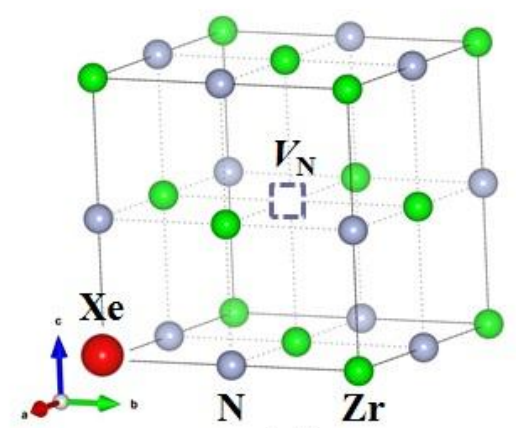

(d)

Figure 6. Atomic configurations of Xe gas atom incorporated in N/Zr divacancy and mixed divacancy in $\mathrm{ZrN}$ : (a) $\mathrm{Xe}$ as a substitution atom at $\mathrm{N}$ site with a $\mathrm{N}$ vacancy as the first nearest neighbor, (b) Xe as a substitution atom slightly deviated from the $\mathrm{Zr}$ site, (c) Xe positioned between the nearest-neighbor $\mathrm{N}$ and $\mathrm{Zr}$ vacancies, slightly close to the $\mathrm{N}$ vacancy, and (d) $\mathrm{Xe}$ as a substitution atom at the $\mathrm{Zr}$ site with a $\mathrm{N}$ vacancy as the second nearest neighbor. Dashed squares represent vacancy sites. 


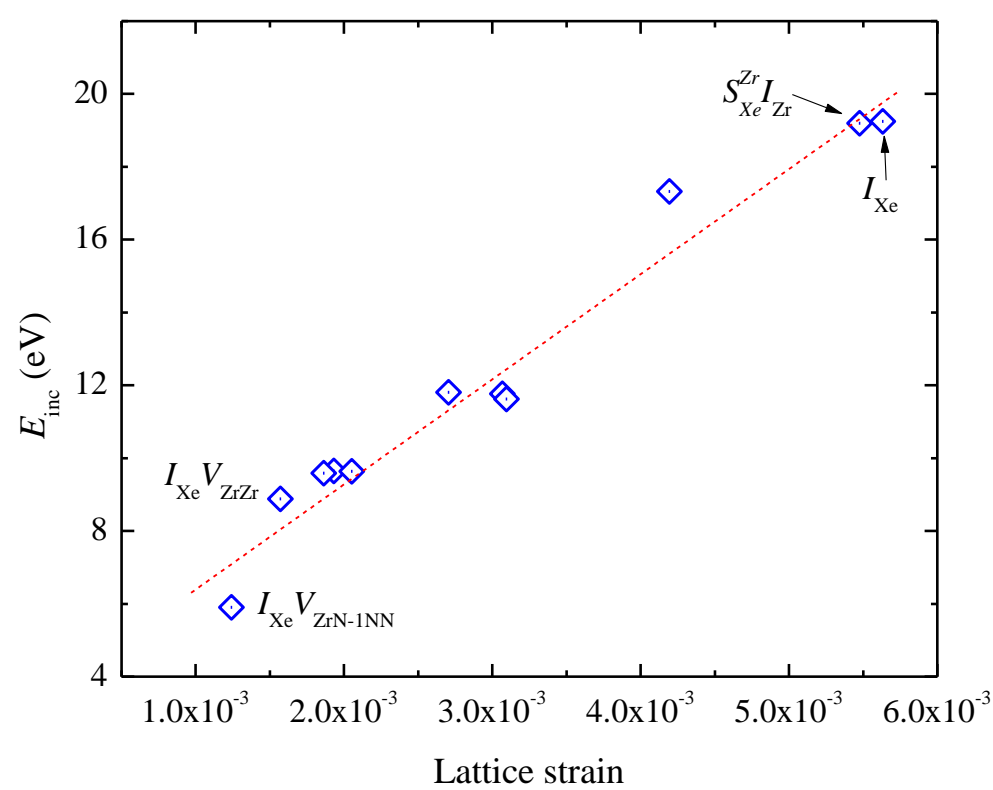

Figure 7. Calculated incorporation energy of $\mathrm{Xe}$ atom in different incorporation sites as a function of lattice strain. The dashed line is a guide to eyes.

By considering the formation energy of the incorporation site, we can obtain the solution energy of fission gas $\mathrm{Xe}$ in $\mathrm{ZrN}$ as described by Eq. (4). The calculated solution energies of Xe in ZrN crystal are shown in Table 4. The first nearest-neighbor Schottky defect $\left(I_{\mathrm{Xe}} V_{\mathrm{ZrN}-1 \mathrm{NN}}\right)$ is found to be the energetically most favorable solution site for $\mathrm{Xe}$ in $\mathrm{ZrN}$, with the Xe solution energy about $3.5 \mathrm{eV}$ lower than that of the configuration with the second lowest energy. The similar solution energy for Xe in incorporation sites $I_{\mathrm{Xe}} V_{\mathrm{Zr}}, S_{\mathrm{Xe}}^{Z r}, I_{\mathrm{Xe}} V_{\mathrm{ZrN}-1 \mathrm{NN}}$ could be due to the relatively large $\mathrm{Zr}$ vacancy site where the $\mathrm{Xe}$ atom prefers to stay. To better understand the difference of incorporation energies, we calculated the bonding energy between the Xe tetrahedral interstitial and the pre-existing singe vacancies or divacancies in $\mathrm{ZrN}$. As shown in Fig. 7, the incorporation energy of $\mathrm{Xe}$ in different configurations is inversely proportional to the bonding energy between the Xe interstitial and single vacancies or divacancies, meaning a strong bonding between $I_{\mathrm{Xe}}$ and vacancies leads to a low incorporation energy of $\mathrm{Xe}$ in the corresponding incorporation site. 


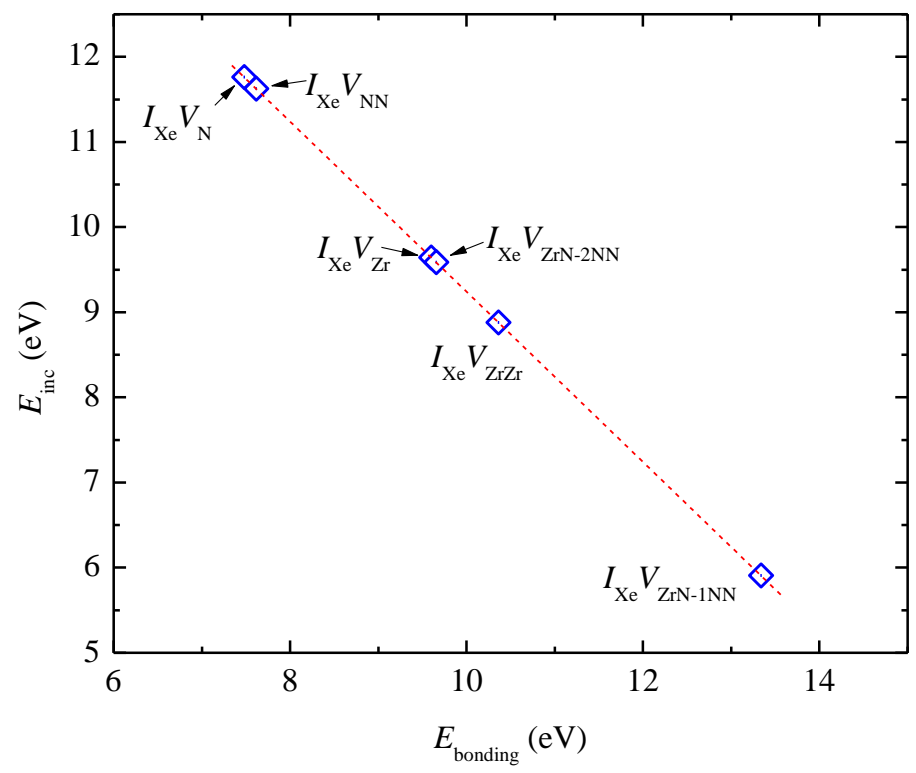

Figure 8. Calculated incorporation energy of Xe in different configurations vs the bonding energy between Xe interstitial and single vacancies or divacancies. The dashed line is a guide to eyes.

Table 4. Xe incorporation, solution, and binding energy in $\mathrm{ZrN}$ (in eV)

\begin{tabular}{|c|c|c|c|c|c|}
\hline Incorporation Site & $\bar{E} E_{\text {inc }}$ & $E_{\mathrm{sol}}^{\mathrm{a}}$ & $E_{\mathrm{sol}}^{\mathrm{b}}$ & $\overline{E_{\text {binding }}}$ & $E_{\text {inc }}$ in $\mathrm{TiN}^{\mathrm{c}}$ \\
\hline$I_{\mathrm{Xe}}$ & 19.24 & 19.24 & 19.24 & - & 21.86 \\
\hline$I_{\mathrm{Xe}} V_{\mathrm{N}}$ & 11.76 & 14.98 & 13.05 & 7.48 & 13.55 \\
\hline$I_{\mathrm{Xe}} V_{\mathrm{Zr}}$ & 9.65 & 12.55 & 10.93 & 9.60 & 14.16 \\
\hline$S_{X e}^{N}$ & 11.80 & 15.02 & 13.09 & - & 13.54 \\
\hline$S_{X e}^{Z r}$ & 9.64 & 12.54 & 10.92 & - & 15.39 \\
\hline$I_{\mathrm{Xe}} V_{\mathrm{NN}}$ & 11.63 & 18.14 & 14.29 & 7.63 & \\
\hline$I_{\mathrm{Xe}} V_{\mathrm{ZrZr}}$ & 8.88 & 15.05 & 11.81 & 10.36 & \\
\hline$I_{\mathrm{Xe}} V_{\mathrm{ZrN}-1 \mathrm{NN}}$ & 5.91 & 8.46 & 8.46 & 13.34 & \\
\hline$I_{\mathrm{Xe}} V_{\mathrm{ZrN}-2 \mathrm{NN}}$ & 9.59 & 12.16 & 12.16 & 9.66 & 13.91 \\
\hline$S_{X e}^{N} I_{N}$ & 17.32 & 23.22 & 23.22 & - & 21.61 \\
\hline$S_{X e}^{Z r} I_{Z r}$ & 19.20 & 33.07 & 33.07 & - & 22.97 \\
\hline
\end{tabular}

${ }^{\mathrm{a}} \mathrm{HCP} \mathrm{Zr}$ metal and $\mathrm{N}_{2}$ gas in vacuum as the reference states for $\mathrm{Zr}$ and $\mathrm{N}$ species.

${ }^{\mathrm{b}}$ Chemical potentials of $\mathrm{Zr}$ and $\mathrm{N}$ species set as $\mu_{\mathrm{Zr}}=-10.14 \mathrm{eV}$ and $\mu_{\mathrm{N}}=-10.23 \mathrm{eV}$, respectively.

${ }^{\mathrm{c}}$ Results from Ref. ${ }^{19}$. 
Because of the critical impact of fission gas bubble induced swelling on nuclear fuels, the incorporation of fission gas has also been studied in several other nuclear materials, including $\mathrm{UC},{ }^{20} \mathrm{UN},{ }^{21} \mathrm{ZrC},{ }^{19} \mathrm{TiN},{ }^{19}$ and $\mathrm{SiC} .{ }^{19}$ We compared the incorporation of the fission gas $\mathrm{Xe}$ in $\mathrm{ZrN}$ with those materials with the same rock salt structure (MX), as shown in Fig. 9. Overall, similar results were obtained for all the materials. The incorporation energies of Xe at the first nearest neighbor Frenkel pair defect $\left(I_{\mathrm{Xe}} V_{M X-1 \mathrm{NN}}\right.$, with $M=\mathrm{Ti}, \mathrm{Zr}$, or $\mathrm{U}$, and $X=\mathrm{C}$ or $\mathrm{N})$ are the lowest among all the incorporation sites for all materials. We notice that the incorporation energies of $\mathrm{Xe}$ are sensitive to the size of vacancy site. For example, the $\mathrm{Xe}$ incorporation energy at the $\mathrm{U}$ vacancy site is much lower than that in the $\mathrm{Ti}$ and $\mathrm{Zr}$ vacancy sites because of the much larger open space at the U lattice site. In comparison, the Xe incorporation energy at the $\mathrm{N}$ vacancy site is close to that at the $\mathrm{C}$ vacancy site because of the similar size of these two atoms.

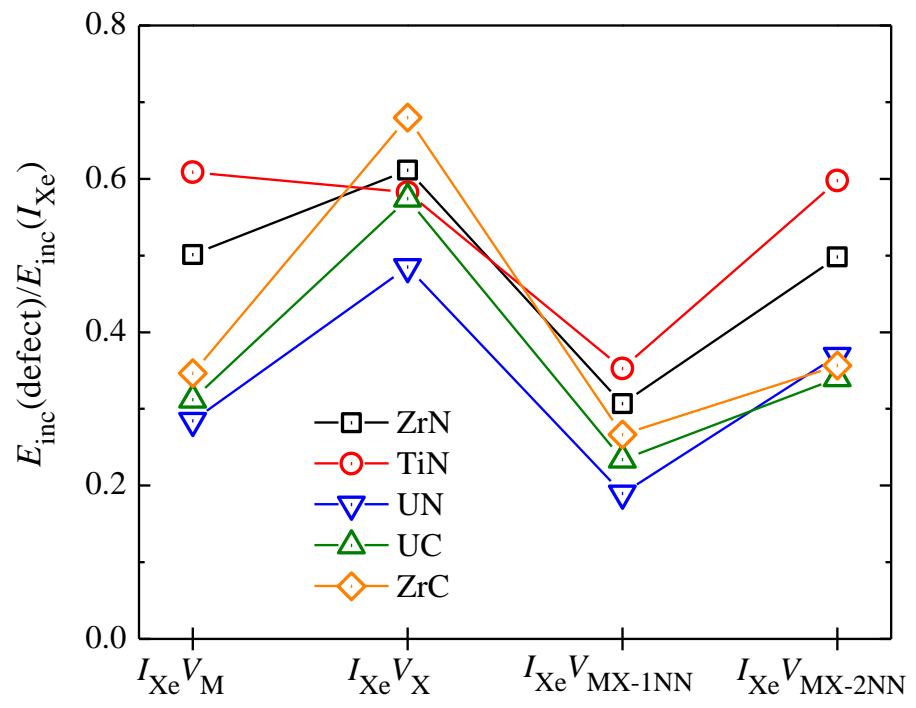

Figure 9. Xe incorporation energy in $\mathrm{ZrN}$ (this work), $\mathrm{TiN},{ }^{19} \mathrm{UN},{ }^{21} \mathrm{UC},{ }^{20}$ and $\mathrm{ZrC}^{19}$ obtained using the same calculations approach. Values are divided by the corresponding interstitial incorporation energy. 
In additional to $\mathrm{Xe}$, we studied the incorporation of two other inert gases, $\mathrm{He}$ and $\mathrm{Kr}$, in a $\mathrm{ZrN}$ crystal. Similar to $\mathrm{Xe}$, we calculated the incorporation and solution energies of these inert gas atoms in the tetrahedral interstitial site $\left(I_{\mathrm{gas}}\right)$, the single vacancy site $\left(I_{\mathrm{gas}} V_{\mathrm{N}}\right.$ and $\left.I_{\mathrm{gas}} V_{\mathrm{Zr}}\right)$, and the mixed divacancy site $\left(I_{\mathrm{gas}} V_{\mathrm{ZrN}-1 \mathrm{NN}}\right)$, as shown in Table 5. Because of the much smaller atomic size of $\mathrm{He}(3.1 \AA)$ as compared with $\mathrm{Kr}(8.8 \AA)$ and $\mathrm{Xe}(10.8 \AA)$, the incorporation energy of the He atoms at the tetrahedral interstitial site is only about one-fifth that of Xe. With unlimited interstitial sites available in the perfect $\mathrm{ZrN}$ crystal, He atoms will be in solution in the tetrahedral position in $\mathrm{ZrN}$ because of its overall lowest solution energy. However, under irradiation conditions most of the He atoms can be trapped in the $\mathrm{Zr}$ vacancy sites in $\mathrm{ZrN}$ due to its lowest incorporation energy in the $\mathrm{Zr}$ vacancy. $\mathrm{Kr}$ gas atoms share a similar incorporation behavior as $\mathrm{Xe}$ in $\mathrm{ZrN}$ because of their close atomic sizes. Both fission gas atoms prefer to occupy the first neighboring mixed divacancy position $\left(I_{\text {gas }} V_{\mathrm{ZrN}-1 \mathrm{NN}}\right)$. We compared our results with the study by Bes et al. ${ }^{19}$ They obtained lightly higher incorporation energies for $\mathrm{He}$ and $\mathrm{Kr}$ in $\mathrm{TiN}$ for reasons similar to those discussed for $\mathrm{Xe}$ in the previous section. To study the effect of atomic size of inert gases on the solution energy, we plot the calculated solution energies of $\mathrm{He}, \mathrm{Kr}$, and $\mathrm{Xe}$ in four different incorporation positions of $\mathrm{ZrN}$ as a function of atomic size of inert gases in Fig. 10. Overall, the solution energies of inert gases in $\mathrm{ZrN}$ show a linear dependence on the atomic size of inert gases.

To summarize, the incorporation of large fission gases, such as $\mathrm{Kr}$ and $\mathrm{Xe}$, in nuclear materials is assisted by the presence of vacancies, and they are mostly trapped at one of the vacancy sites. Vacancies can reduce the local stress and lattice distortions induced in the host lattice by fission gas incorporation and therefore reduce the energy cost of its incorporation. This phenomenon is responsible for the generally low solubility of $\mathrm{Kr}$ and $\mathrm{Xe}$ in nuclear materials and their precipitation into gas bubbles. For comparison, small He gas atoms may be stabilized in the lattice of materials as interstitial atoms. 
Table 5. He and $\mathrm{Kr}$ incorporation, solution and binding energy in $\mathrm{ZrN}$ (in eV)

\begin{tabular}{lccccc}
\hline \hline Incorporation Site & $E_{\text {inc }}$ & $E_{\text {sol }}{ }^{\mathrm{a}}$ & $E_{\text {sol }}^{\mathrm{b}}$ & $E_{\text {binding }}$ & $E_{\text {inc }}$ in $\mathrm{TiN}^{\mathrm{c}}$ \\
\hline$I_{\mathrm{He}}$ & 3.98 & 3.98 & 3.98 & - & 4.7 \\
$I_{\mathrm{He}} V_{\mathrm{N}}$ & 3.11 & 6.33 & 4.40 & 0.88 & 3.23 \\
$I_{\mathrm{He}} V_{\mathrm{Zr}}$ & 0.73 & 3.64 & 2.02 & 3.25 & 1.13 \\
$I_{\mathrm{He}} V_{\mathrm{ZrN}-1 \mathrm{NN}}$ & 1.44 & 4.00 & 4.00 & 2.54 & \\
$I_{\mathrm{Kr}}$ & 15.46 & 15.46 & 15.46 & - & 18.58 \\
$I_{\mathrm{Kr}} V_{\mathrm{N}}$ & 9.22 & 12.44 & 10.51 & 6.24 & 9.85 \\
$I_{\mathrm{Kr}} V_{\mathrm{Zr}}$ & 7.13 & 10.04 & 8.42 & 8.33 & 11.23 \\
$I_{\mathrm{Kr}} V_{\mathrm{ZrN}-1 \mathrm{NN}}$ & 4.48 & 7.04 & 7.04 & 10.97 & \\
\hline \hline
\end{tabular}

${ }^{a} \mathrm{HCP} \mathrm{Zr}$ metal and $\mathrm{N}_{2}$ gas in a vacuum as the reference states for $\mathrm{Zr}$ and $\mathrm{N}$ species.

${ }^{\mathrm{b}}$ Chemical potentials of $\mathrm{Zr}$ and $\mathrm{N}$ species set as $\mu_{\mathrm{Zr}}=-10.14 \mathrm{eV}$ and $\mu_{\mathrm{N}}=-10.23 \mathrm{eV}$, respectively.

${ }^{\mathrm{c}}$ Reference ${ }^{19}$.

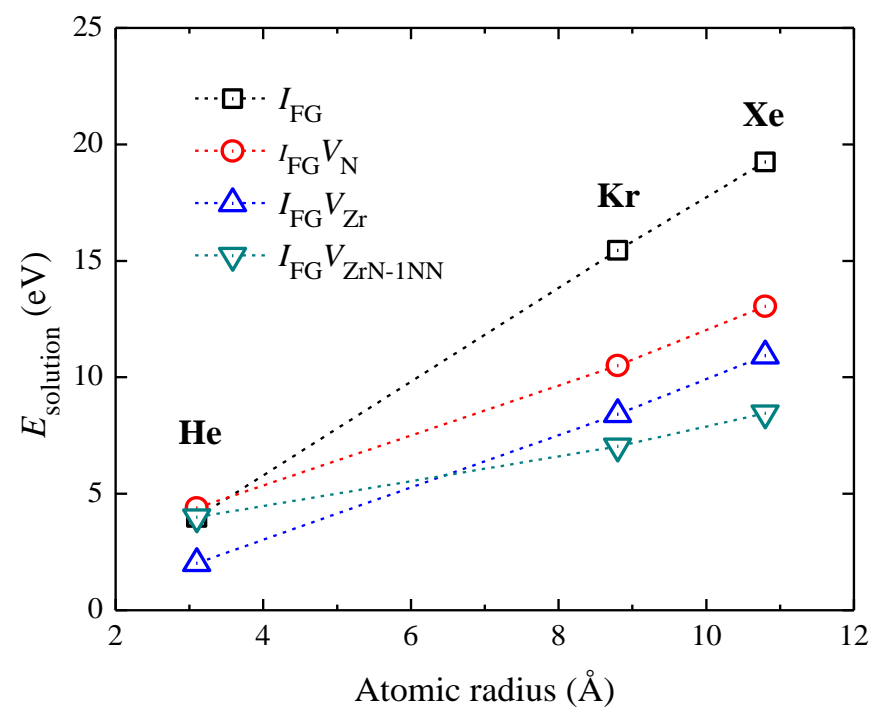

Figure 10. Calculated solution energies of the inert gas atoms $\mathrm{He}, \mathrm{Kr}$, and $\mathrm{Xe}$ in four incorporation positions of $\mathrm{ZrN}$. The chemical potentials of the $\mathrm{Zr}$ and $\mathrm{N}$ species as $\mu_{\mathrm{Zr}}=-$ $10.14 \mathrm{eV}$ and $\mu_{\mathrm{N}}=-10.23 \mathrm{eV}$, respectively, were used for calculating the defect formation energies. Dotted lines are guides to eyes. 


\section{E. Xe migration in $\mathrm{ZrN}$}

In this section we discuss the migration behavior of fission gases in $\mathrm{ZrN}$ crystal. $\mathrm{Xe}$ gas atoms can migrate in $\mathrm{ZrN}$ through two potential mechanisms: interstitial diffusion and vacancy-assisted diffusion. The first scenario is most relevant when there is a lack of vacancies near the interstitial as well as in the event of fission gases having exhausted all available vacancy sites. In $\mathrm{ZrN}$, a Xe interstitial can occupy two types of equilibrium interstitial positions, i.e., the tetrahedral and octahedral sites. The tetrahedral site provides the lowest energy of the system, whereas the octahedral site serves as a saddle point. Xe gas atoms in the tetrahedral interstitial site can diffuse to the nearest tetrahedral site through the $<100>$ direction, as illustrated in Fig. 11(a). The migration barrier of the Xe interstitial though the interstitial mechanism is predicted to be $1.47 \mathrm{eV}$, as shown in Fig. 11(b).
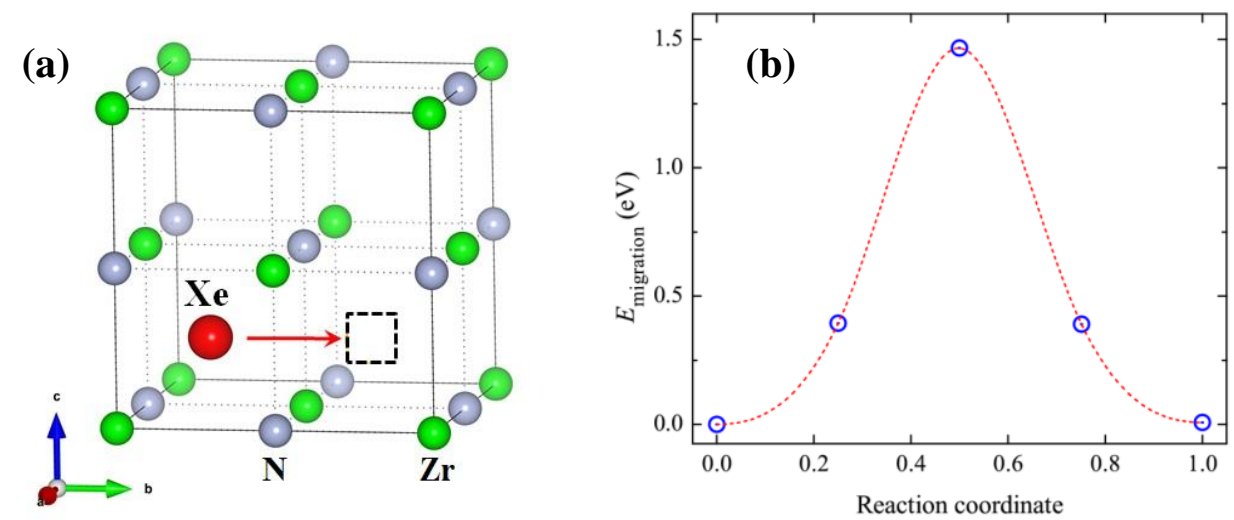

Figure 11. (a) Migration path of an interstitial Xe atom between two tetrahedral interstitial positions in $\mathrm{ZrN}$, and (b) migration barrier of an interstitial Xe atom along the described path. Dotted line is a guide to eyes.

Vacancy-assisted diffusion can occur on a face-centered cubic N/Zr sublattice or on mixed $\mathrm{N}$ and $\mathrm{Zr}$ sites, that is, a $\mathrm{N} / \mathrm{Zr}$ divacancy or mixed divacancy, respectively. We investigated the diffusion capability of a cluster consisting of a single gas atom and two vacancies. In such a cluster the gas atom either adopts the atomic site of one of the vacancies 
or is positioned between the two vacancies. In the $\mathrm{ZrN}$ crystal, the migration of the $\mathrm{Xe}$ gas atom through the nitrogen or zirconium divacancy requires two steps: (1) migration of the substitutional Xe atom to a nearby vacancy and creation of a new vacancy, and (2) migration of the new vacancy to one of the nearest neighbors of the Xe atom, as illustrated in Figs. 12 and 13. For the N/Zr divacancy, the Xe gas atom adopts one of the vacancies and diffuses to the other vacancy site, as shown in Figs. 12(a) and 13(a). The calculated migration barriers of a Xe atom in the $\mathrm{N}$ and $\mathrm{Zr}$ divacancies are shown in Figs. 12(c) and 13(c). Because of the larger open space of the $\mathrm{Zr}$ vacancy compared with that of $\mathrm{N}$, the Xe migration energy in the $\mathrm{Zr}$ divacancy $(0.45 \mathrm{eV})$ is much lower than that in the $\mathrm{N}$ divacancy $(2.44 \mathrm{eV})$. To complete the migration of the substitutional Xe-vacancy associate, the $\mathrm{N} / \mathrm{Zr}$ vacancy has to migrate to one of the nearest neighbors of the Xe atom, as shown in Figs. 12(b) and 13(b). The migration barriers of the $\mathrm{N}$ and $\mathrm{Zr}$ vacancy accompanied by $\mathrm{Xe}$ are predicted to be $2.96 \mathrm{eV}$ and $3.86 \mathrm{eV}$, respectively. In both cases, the migration of vacancies requires more energy than that of Xe. Therefore, the overall migration barriers of the $\mathrm{Xe}$ gas atom in the $\mathrm{ZrN}$ assisted $\mathrm{N}$ and $\mathrm{Zr}$ divacancies are predicted to be $2.96 \mathrm{eV}$ and $3.86 \mathrm{eV}$, respectively.

The Xe gas atoms can also diffuse through the mixed $\mathrm{N}$ and $\mathrm{Zr}$ vacancy sites (Schottky defects). As illustrated in Fig. 14, the migration of a Xe gas atom assisted by mixed $\mathrm{N}$ and $\mathrm{Zr}$ vacancies requires at least three steps: (1) migration of the substitutional $\mathrm{Xe}$ atom to the $\mathrm{N}$ vacancy site and creation of a $\mathrm{Zr}$ vacancy, (2) migration of the new $\mathrm{Zr}$ vacancy to the first nearest neighbor of the Xe atom and formation of a stable Xe-Schottky defect associate, and (3) migration of the $\mathrm{N}$ vacancy to the second nearest neighbor of the $\mathrm{Zr}$ vacancy. Figure 14(b) shows the calculated migration energies along the described migration paths. The migration barriers are predicted to be $5.43 \mathrm{eV}, 1.09 \mathrm{eV}$, and $4.21 \mathrm{eV}$ for the migrations of the substitutional $\mathrm{Xe}$ atom, $\mathrm{Zr}$ vacancy, and $\mathrm{N}$ vacancy, respectively. Therefore, the overall migration barrier of the $\mathrm{Xe}$ gas atom through the mixed $\mathrm{Zr}$ and $\mathrm{N}$ vacancies in $\mathrm{ZrN}$ is $5.43 \mathrm{eV}$, 
determined by the slowest migration step, that is, the migration of the substitutional Xe atom in $\mathrm{ZrN}$.

To summarize, the migration of a $\mathrm{Xe}$ atom through the interstitial mechanism is energetically more favorable than that through the vacancy-assisted diffusion. At low temperatures, therefore, the fission gas Xe diffuse mainly through interstitials or existing grain boundaries in $\mathrm{ZrN}$, whereas at high temperatures the $\mathrm{Xe}$ gas atoms may diffuse in $\mathrm{ZrN}$ assisted by vacancies, especially nitrogen vacancies. Under irradiation conditions, Xe atoms initially end up in tetrahedral interstitial sites and continue to diffuse until they meet the surface or a trap, which may be a single vacancy but more probably a divacancy, a bigger cluster of point defects, a loop, or other radiation defects produced by recoil atoms. ${ }^{22}$ When meeting such a defect, the fission gas atoms will be trapped until the traps get mobile. At the typical operation temperature of research reactors (less than $200^{\circ} \mathrm{C}$ ), the fission gases will be mostly trapped in divacancies and become almost immobile in $\mathrm{ZrN}$.

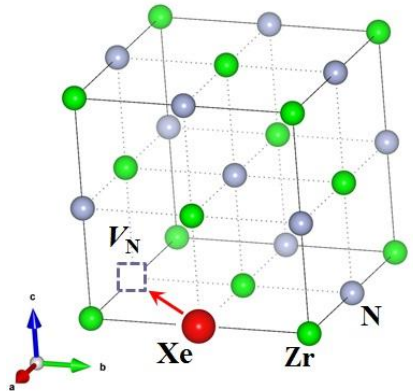

(a)

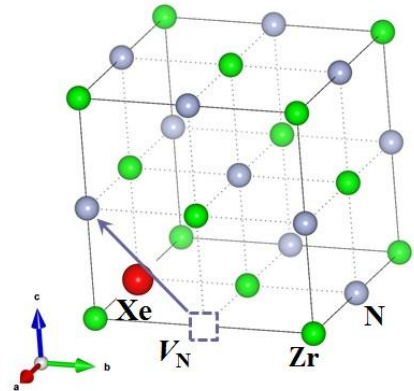

(b) 


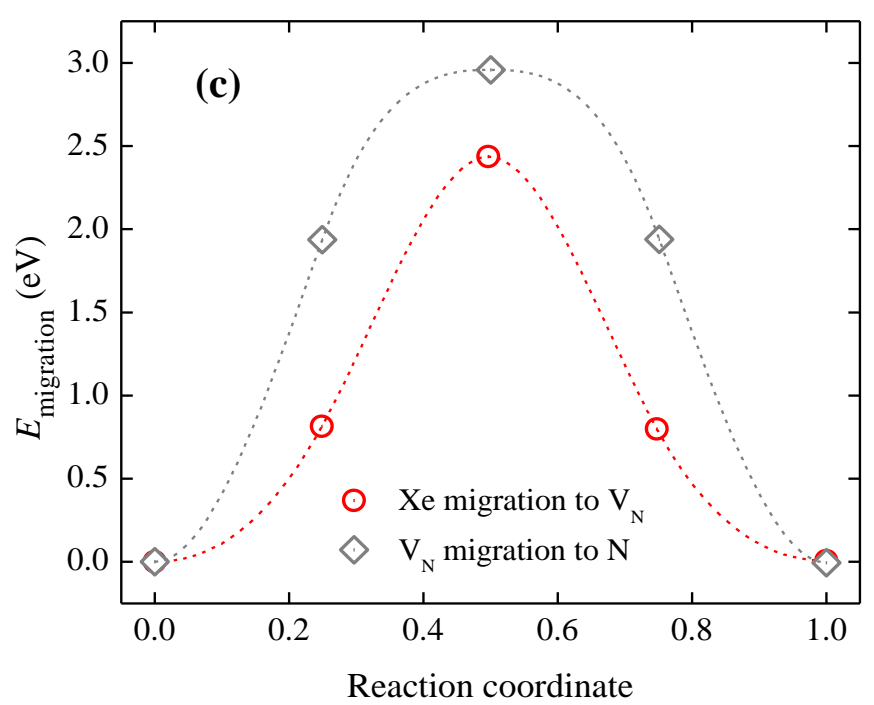

Figure 12. (a) and (b) Migration paths of vacancy-assisted Xe diffusion in the nitrogen sublattice in $\mathrm{ZrN}$. (c) Migration barriers of the $\mathrm{Xe}$ and nitrogen vacancy migrations as illustrated in (a) and (b), respectively. Dashed lines are guides to eyes.

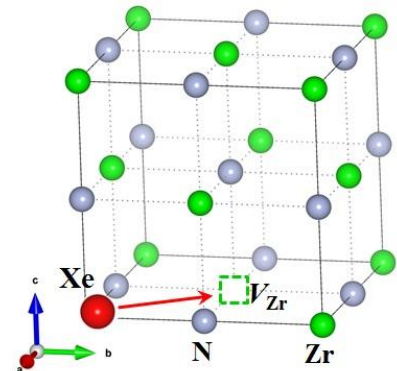

(a)

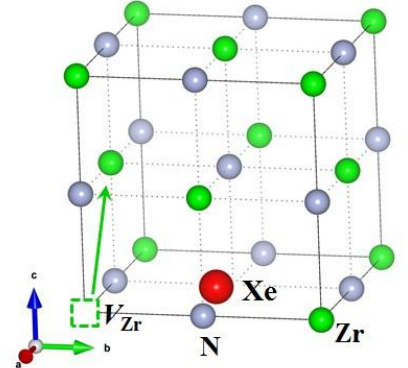

(b) 


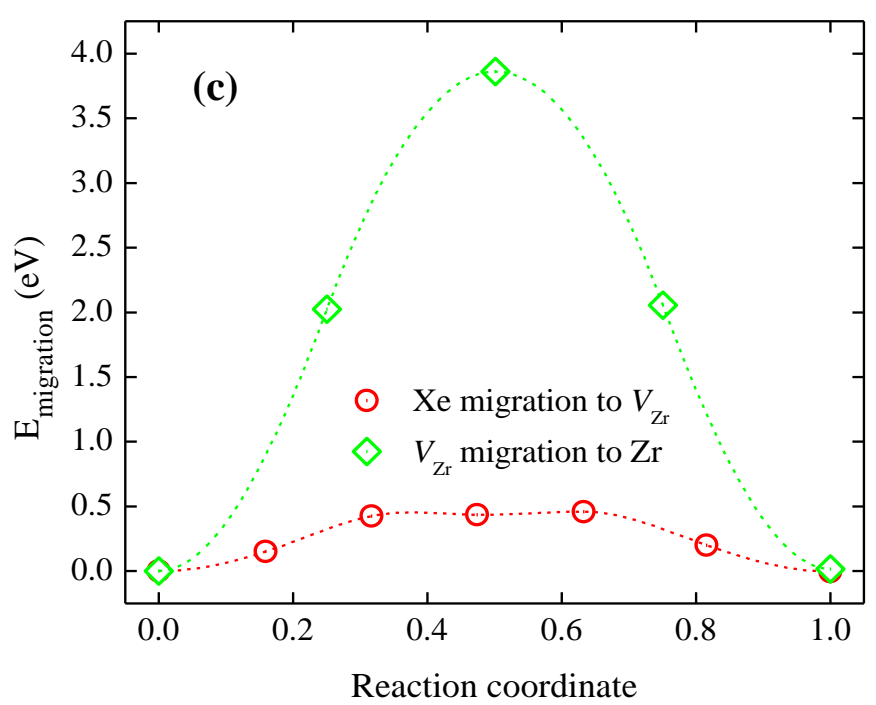

Figure 13. (a) and (b) Migration paths of vacancy-assisted Xe diffusion in the zirconium sublattice in $\mathrm{ZrN}$. (c) Migration barriers of the $\mathrm{Xe}$ and zirconium vacancy migrations as illustrated in (a) and (b), respectively. Dashed lines are guides to eyes.

(a)

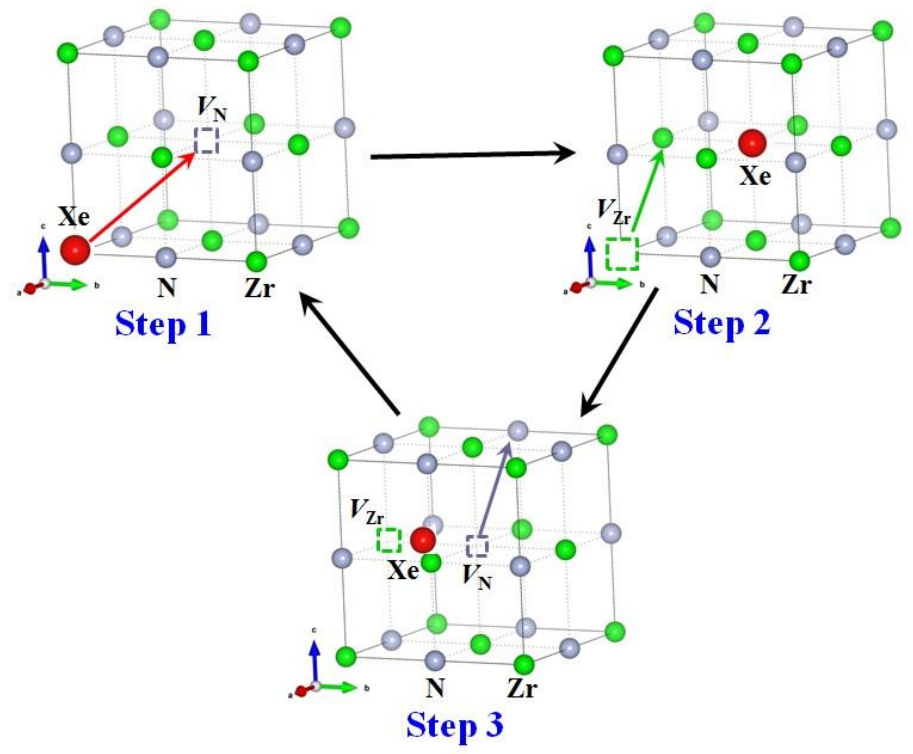




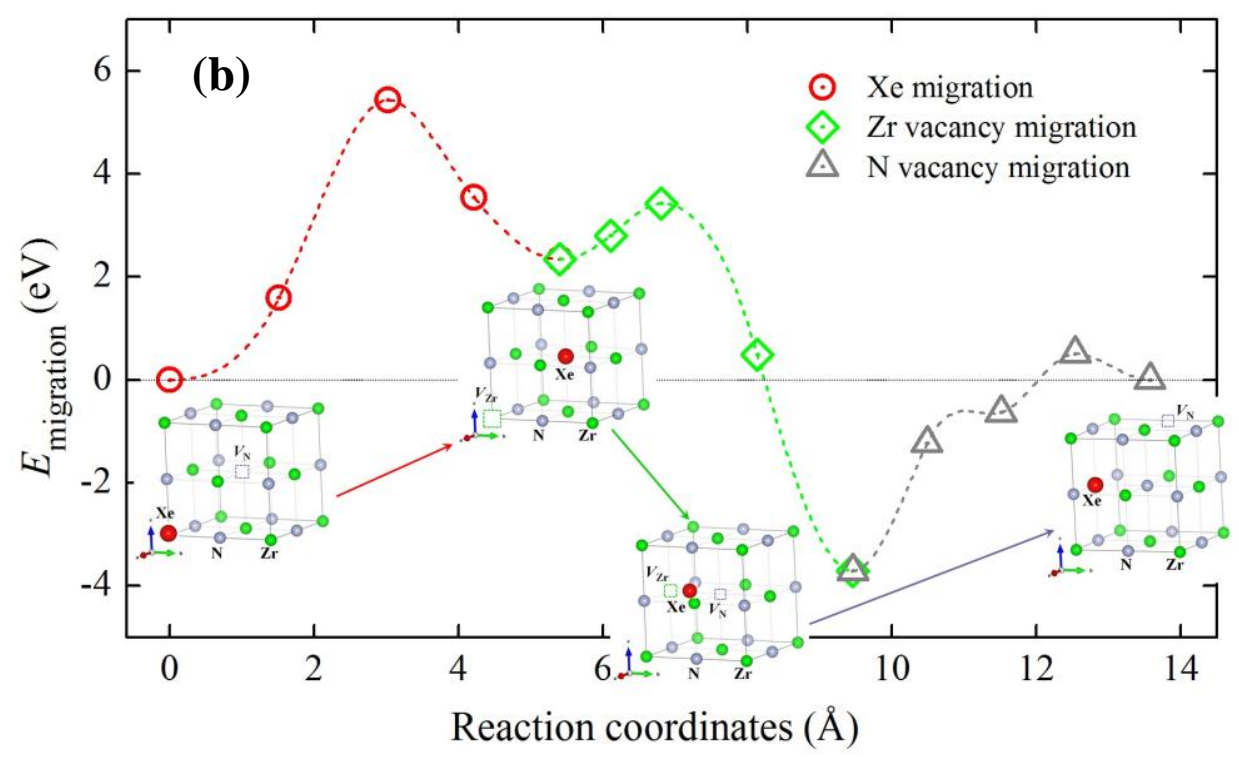

Figure 14. (a) Migration paths of mixed zirconium and nitrogen vacancy-assisted Xe diffusion in $\mathrm{ZrN}$. (b) Migration barriers of $\mathrm{Xe}$, zirconium, and nitrogen vacancies migrations as illustrated in (a). Dashed lines are guides to eyes.

\section{SUMMARY}

Using first-principles calculations, we conducted a systematic study of the incorporation and migration of the fission gas $\mathrm{Xe}$ in $\mathrm{ZrN}$ as a diffusion barrier for U-Mo dispersion fuels. The formations of several single defects and defect clusters in $\mathrm{ZrN}$, including vacancies, interstitials, divacancies, Frenkel pairs, and Schottky defects were investigated. Studies of several configurations of $\mathrm{Zr} / \mathrm{N}$ interstitials and Frenkel pair defects show that the most stable self-interstitials for $\mathrm{Zr}$ and $\mathrm{N}$ atoms are predicted to be tetrahedral and $\langle 111\rangle$ dumbbell interstitials, respectively. The defect distance plays an important role in the stability of defect clusters, such as divacancies, Frenkel pairs, and Schottky defects. We also studied the effects of the chemical potentials of $\mathrm{N}$ and $\mathrm{Zr}$ species on the defect formation energies and found that only the formation energies of Frenkel pairs and Schottky defects are not affected by the chemical potential. Incorporation energies of the fission gas Xe in 14 incorporation sites of $\mathrm{ZrN}$, including the tetrahedral site, $\mathrm{N} / \mathrm{Zr}$ single-vacancy site, substitution site on the $\mathrm{N} / \mathrm{Zr}$ 
lattice site, N/Zr divacancy site, Schottky defect, and N/Zr vacancy site in the N/Zr Frenkel pair defect were predicted. Based on the calculated solution energy of $\mathrm{Xe}$ in $\mathrm{ZrN}$, the first nearest-neighbor Schottky defect is determined to be the most stable incorporation site, in which the $\mathrm{Xe}$ atom sits somewhere between the $\mathrm{Zr}$ and $\mathrm{N}$ vacancies. Comparison of the incorporation energy of $\mathrm{Xe}$ in $\mathrm{ZrN}$ with several other nuclear materials, including TiN, UN, $\mathrm{UC}$, and $\mathrm{ZrC}$, shows that the incorporation energies of $\mathrm{Xe}$ are closely related to the size of vacancy sites. The predicted solution energies of three inert gases in $\mathrm{ZrN}$, namely, $\mathrm{He}, \mathrm{Kr}$, and Xe, show a linear dependence on the atomic size of the gas atoms. Furthermore, we studied the migration fission gas $\mathrm{Xe}$ in $\mathrm{ZrN}$ through two potential migration mechanisms: interstitial and vacancy-assisted diffusions. We compared the migration behaviors of $\mathrm{Xe}$ atoms in $\mathrm{N} / \mathrm{Zr}$ divacancy and Schottky defects with that through tetrahedral interstitial sites. The migration barrier with interstitial diffusion is much lower than that through vacancies. Therefore, at the typical operating temperatures of research reactors, $\mathrm{ZrN}$ coating can serve as an effective diffusion barrier against the fission gases generated inside the U-Mo fuel particles. At high temperatures, such as encountered in the nitride fuels, fission gas Xe may diffuse in $\mathrm{ZrN}$ aided by vacancies.

\section{ACKNOWLEDGMENTS}

This work is sponsored by the U.S. Department of Energy, National Nuclear Security Administration (NNSA), Office of Material Management and Minimization (NA-23) Reactor Conversion Program. The material is also based upon work supported by the U.S> Department of Energy, Office of Science, under Contract DE-AC02-06CH11357. Use of the Center for Nanoscale Materials, an Office of Science user facility, was supported by the U.S. Department of Energy, Office of Science, Office of Basic Energy Sciences, under Contract No. DE-AC02-06CH11357. We gratefully acknowledge the computing resources provided on Blues, a high-performance computing cluster operated by the Laboratory Computing 
Resource Center at Argonne National Laboratory. 


\section{REFERENCES}

3

4

5

M. K. Meyer, G. L. Hofman, S. L. Hayes, C. R. Clark, T. C. Wiencek, J. L. Snelgrove, R. V. Strain, and K. H. Kim, Journal of Nuclear Materials 304, 221 (2002).

R. Jungwirth, T. Zweifel, H. Y. Chiang, W. Petry, S. Van den Berghe, and A. Leenaers, Journal of Nuclear Materials 434, 296 (2013).

S. Van den Berghe, W. Van Renterghem, and A. Leenaers, Journal of Nuclear Materials 375, 340 (2008).

A. Leenaers, S. Van den Berghe, and C. Detavernier, Journal of Nuclear Materials 440, 220 (2013).

Y. S. Kim, J. M. Park, K. H. Lee, B. O. Yoo, H. J. Ryu, and B. Ye, Journal of Nuclear Materials 454, 238 (2014).

W. Chubb, R. F. Hilbert, V. W. Storhok, and D. L. Keller, Materials Science and Engineering 9, 293 (1972).

Z.-G. Mei, A. M. Yacout, Y. S. Kim, G. Hofman, and M. Stan, Journal of Nuclear Materials (2016).

L. Tsetseris, N. Kalfagiannis, S. Logothetidis, and S. T. Pantelides, Physical Review Letters 99, 125503 (2007).

L. Tsetseris, N. Kalfagiannis, S. Logothetidis, and S. T. Pantelides, Physical Review B 76, 224107 (2007).

L. Tsetseris, N. Kalfagiannis, S. Logothetidis, and S. T. Pantelides, Physical Review B 78, 094111 (2008).

L. Tsetseris, S. Logothetidis, and S. T. Pantelides, Surface and Coatings Technology 204, 2089 (2010).

M. Pukari, P. Olsson, and N. Sandberg, Journal of Nuclear Materials 438, 7 (2013).

G. Kresse and J. Furthmüller, Phys. Rev. B 54, 11169 (1996).

G. Kresse and D. Joubert, Phys. Rev. B 59, 1758 (1999).

J. P. Perdew, K. Burke, and M. Ernzerhof, Phys. Rev. Lett. 77, 3865 (1996).

A. N. Christensen, Acta Chemica Scandinavica A 29, 563 (1975).

G. Henkelman, B. P. Uberuaga, and H. Jónsson, The Journal of Chemical Physics 113, 9901 (2000).

R. Bès, P. Martin, E. Vathonne, R. Delorme, C. Sabathier, M. Freyss, M. Bertolus, and P. Glatzel, Applied Physics Letters 106, 114102 (2015).

R. Bès, Y. Pipon, N. Millard-Pinard, S. Gavarini, and M. Freyss, Physical Review B 87, 024104 (2013).

M. Freyss, Physical Review B 81, 014101 (2010).

M. Klipfel and P. Van Uffelen, Journal of Nuclear Materials 422, 137 (2012).

H. Matzke and F. Springer, Radiation Effects 2, 11 (1969).

\section{Government License}

The submitted manuscript has been created by UChicago Argonne, LLC, Operator of Argonne National Laboratory (“Argonne"). Argonne, a U.S. Department of Energy Office of Science laboratory, is operated under Contract No. DE-AC02-06CH11357. The U.S. Government retains for itself, and others acting on its behalf, a paid-up nonexclusive, irrevocable worldwide license in said article to reproduce, prepare derivative works, distribute copies to the public, and perform publicly and display publicly, by or on behalf of the Government. The Department of Energy will provide public access to these results of 
federally sponsored research in accordance with the DOE Public Access Plan. http://energy.gov/downloads/doe-public-access-plan. 
(a)
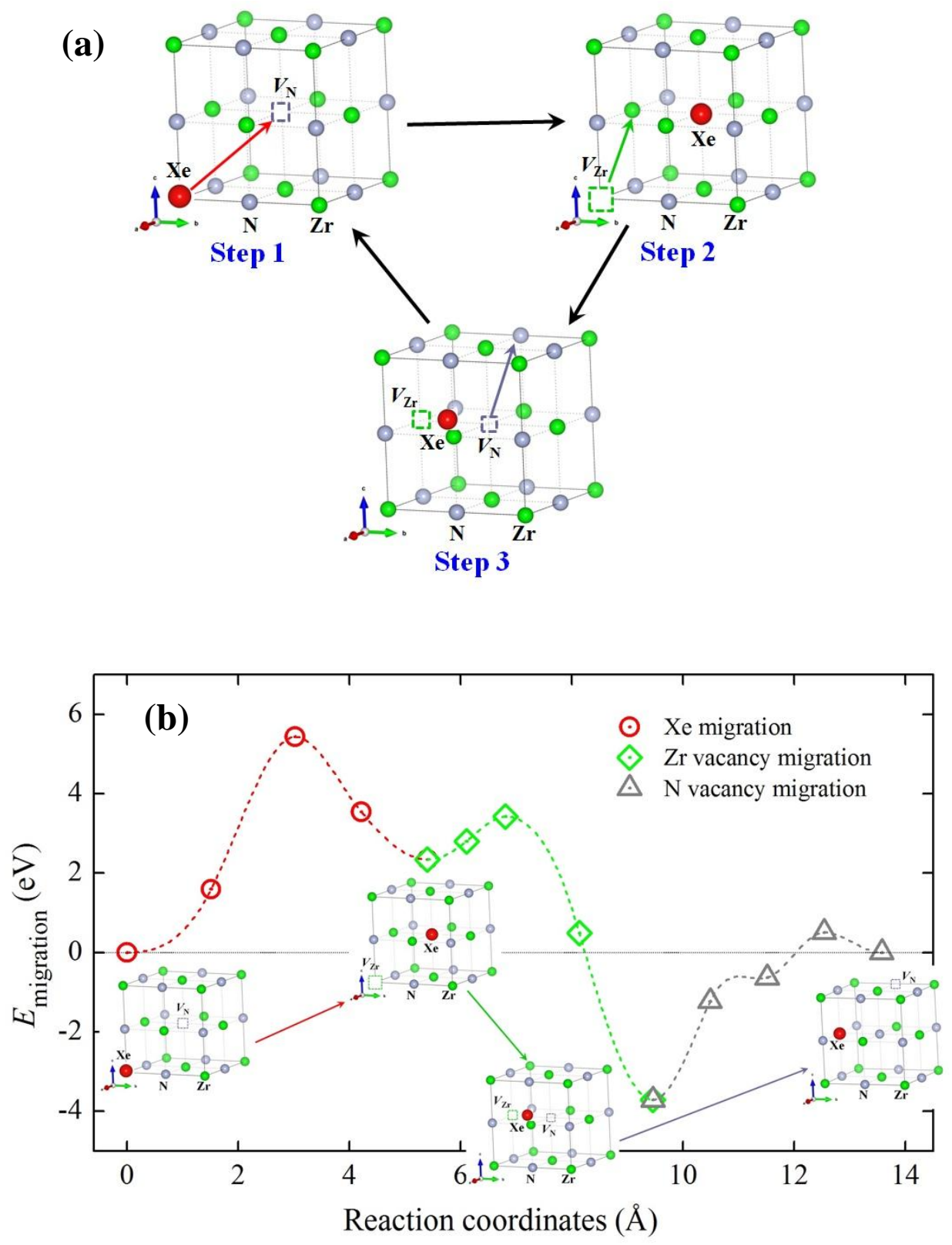

Migration path and barrier of mixed zirconium and nitrogen vacancy-assisted Xe diffusion in $\mathrm{ZrN}$. 